\title{
The interaction of adverse childhood experiences and gender as risk factors for depression and anxiety disorders in US adults: a cross-sectional study
}

Robert C. Whitaker ${ }^{1,2,3,4^{*}}$, Tracy Dearth-Wesley ${ }^{1,2,3}$, Allison N. Herman ${ }^{1,2,3}$, Amy E. Block ${ }^{1,2,3}$, Mary Howard Holderness ${ }^{1,2,3}$, Nicholas A. Waring ${ }^{1,2,3}$ and J. Michael Oakes ${ }^{5}$

\begin{abstract}
Background: Exposure to adverse childhood experiences (ACEs) and being female are distinct risk factors for having a major depressive episode (MDE) or an anxiety disorder (AD) in adulthood, but it is unclear whether these two risk factors are synergistic. The purpose of this study was to determine whether exposure to ACEs and being female are more than additive (synergistic) in their association with MDE and AD in US adults.

Methods: We pooled cross-sectional survey data in the Midlife in the United States study from two nationallyrepresentative cohorts of English-speaking US adults. Data from the first cohort were collected in 2004-2006 and from the second in 2011-2014. Data from both cohorts included the 12-month prevalence of MDE and AD (generalized anxiety disorder or panic disorder) assessed with the Composite International Diagnostic Interview Short Form, gender (here termed female and male), and the count of five categories of exposure to ACEs: physical, sexual, or emotional abuse; household alcohol or substance abuse; and parental separation or divorce.

Results: Of the 5834 survey respondents, 4344 (74.5\%) with complete data on ACEs were included in the analysis. Mean (SD) age was 54.1 (13.8) years and 53.9\% were female. The prevalences of MDE, AD, and exposure to 3-5 categories of ACEs were 13.7, 10.0, and 12.5\%, respectively. After adjusting for covariates (age, race, and current and childhood socioeconomic disadvantage), for those with both risk factors (female and 3-5 ACEs) the prevalence of MDE was $26.9 \%$. This was $10.2 \%$ (95\% Cl: 1.8, 18.5\%) higher than the expected prevalence based on the additive associations of the two risk factors. The adjusted prevalence of AD among females with 3-5 ACEs was $21.9 \%$, which was $11.4 \%$ (95\% Cl: 4.0, 18.9\%) higher than the expected prevalence.
\end{abstract}

Conclusions: For both MDE and AD, there was synergy between the two risk factors of exposure to ACEs and being female. Identification and treatment of MDE and AD may benefit from understanding the mechanisms involved in the synergistic interaction of gender with ACEs.

Keywords: Depression, Anxiety, Adverse childhood experiences, Child abuse, Sex, Gender identity

\footnotetext{
* Correspondence: robert.whitaker@bassett.org

'Columbia-Bassett Program, Vagelos College of Physicians and Surgeons,

Columbia University, New York, NY, USA

${ }^{2}$ Columbia-Bassett Program, Bassett Medical Center, Cooperstown, NY, USA

Full list of author information is available at the end of the article
}

C C The Author(s). 2021 Open Access This article is licensed under a Creative Commons Attribution 4.0 International License, which permits use, sharing, adaptation, distribution and reproduction in any medium or format, as long as you give appropriate credit to the original author(s) and the source, provide a link to the Creative Commons licence, and indicate if changes were made. The images or other third party material in this article are included in the article's Creative Commons licence, unless indicated otherwise in a credit line to the material. If material is not included in the article's Creative Commons licence and your intended use is not permitted by statutory regulation or exceeds the permitted use, you will need to obtain permission directly from the copyright holder. To view a copy of this licence, visit http://creativecommons.org/licenses/by/4.0/ The Creative Commons Public Domain Dedication waiver (http://creativecommons.org/publicdomain/zero/1.0/) applies to the data made available in this article, unless otherwise stated in a credit line to the data. 


\section{Introduction}

Adverse childhood experiences (ACEs), such as exposure to emotional, physical, or sexual abuse, are common [1] and associated with an increased risk of major depression and anxiety disorders in adulthood [2]. There are plausible socio-biological mechanisms to explain how the early life stress of ACEs contributes to the later risk of these disorders [3-6]. Separate from the risk factor of ACEs, females are at higher risk than males for these disorders [7-10]. Similar to ACEs, the mechanisms conferring risk for females appear to involve factors which are both social (gender) [11-14] and biological (sex) [15-17]. Gender and sex are distinct social and biological constructs, but they are inter-related, transcend binary designations, and act together in contributing to health outcomes [18]. For brevity, however, we henceforth only use the terms "gender" and "female/male."

Although exposure to ACEs and being female are distinct causal risk factors for depression and anxiety, it is unclear whether these two factors are synergistic, or more than additive, in their associations. There are plausible socio-biological mechanisms of interaction between these risk factors. At different developmental stages, sex differences affect the brain in ways that can alter the stress response of the nervous, endocrine, and immune systems $[19,20]$. For example, female sex hormones can enhance the neuro-immune response to ACEs, making females more susceptible to depression and anxiety [21-23]. The nervous, endocrine, and immune systems work together in response to physical and psychological threats, including violence, abandonment, and discrimination. It remains unclear whether any female/male differences in the biobehavioral responses to such threats reflect evolutionary biology [24, 25] or gender socialization [26]. However, in sexist and patriarchal societies, many females experience chronic stress [27], and gender norms can lead to females holding distorted and negative perceptions and beliefs about their worth and functioning [28]. As in other preventable forms of discrimination, such as racism, chronic exposure to sexism, especially if experienced throughout development and in prior generations, can initiate neuro-endocrine-immune and behavioral processes that may directly cause anxiety and depression $[29,30]$. Exposure to sexism, like racism, can also reduce the likelihood that the child will be able to buffer the effects of other adversities on their mental health. There is some evidence of synergy among ACEs on mental health disorders [31, 32], and sexism might potentially be viewed as an additional developmental trauma that acts synergistically with other ACEs.

Despite these plausible mechanisms of interaction between ACEs and gender, there is no clear epidemiologic evidence of synergy between these two risk factors in relation to the outcomes of major depression or anxiety disorders. Evaluating the presence of interaction as synergy requires a different approach to data analysis than testing for interaction as effect modification (or moderation) [33, 34]. Assessing synergy involves determining whether two putative causal risk factors when present together (being female and exposed to ACEs, in this instance) is associated with a greater observed risk of the outcome (major depression or anxiety disorders) than expected, where the expected risk is the sum of the two separate risks when each is present without the other. We identified seven studies [35-41] that examined the two risk factors using population samples, assessed major depression or anxiety disorders with measures based on the Diagnostic and Statistical Manual of Mental Disorders (DSM), and assessed exposure to at least three categories of ACEs. In five of these studies [36, 38-41] the authors performed a statistical test of interaction between ACEs and gender, but none found evidence of a significant interaction. Each study presented statistical tests of interaction on the multiplicative scale. Statistically significant and clinically meaningful interaction can be missed if one only tests for interaction on a multiplicative scale and not also on the additive scale, which tests for a significant departure from the additive associations of two risk factors [33]. In addition, none of these studies reported the prevalence of major depression or anxiety disorders for every risk strata defined by combinations of the two risk factors, as is recommended in evaluating interaction as synergy [42]. In two studies that did stratify by both risk factors $[35,37]$, the authors did not perform any statistical tests of interaction or estimate risk differences between strata. By employing methods that stratify the data by combinations of the two risk factors and identify significant departures from the additive associations [34], we can potentially identify synergy between ACEs and gender that may have been previously overlooked. This synergy has important implications for both the prevention and treatment of depression and anxiety disorders. Evidence of synergy would bring more attention to the possibility that sexism is a modifiable cause of these disorders that interacts with ACEs. Acting on that evidence in both prevention and treatment may help reduce the large burden of depression and anxiety among females that is attributable to ACEs [43].

Using data from a nationally-representative sample of US adults, we examined whether exposure to ACEs and being female are synergistic risk factors in their association with the 12-month prevalence of a major depressive episode (MDE) and an anxiety disorder (AD) (panic disorder and/or generalized anxiety disorder). 


\section{Methods}

\section{Study population and design}

We used survey data from the Midlife in the United States (MIDUS) study [44], pooling data from two different MIDUS cohorts. Participants were recruited through random-digit-dialing, and the cohorts were designed to be representative of non-institutionalized, English-speaking adults living in the contiguous United States. We only included MIDUS participants who were recruited through random-digit-dialing sampling. Data were collected first by phone interview and then by mailed self-administered questionnaire (SAQ); the same survey items were used with both cohorts. The first cohort $(N=2257)$ was surveyed in 2004-2006 (MIDUS 2, M2) [45, 46], and the second cohort $(N=3577)$ in 2011-2014 (MIDUS Refresher, MR1) $[47,48]$. For this cross-sectional analysis we combined data from both cohorts $(N=5834[2257+3577])$. Because the MIDUS data we used were de-identified and publicly available [49], our study did not require institutional review board approval.

\section{Measures \\ Depression and anxiety disorders}

The 12-month prevalence of a major depressive episode (MDE), panic disorder (PD), and generalized anxiety disorder (GAD) were each assessed by phone interview using items from the Composite International Diagnostic Interview Short Form (CIDI-SF) [50-53]. We combined those with PD and/or GAD into one group called anxiety disorder (AD), and we assessed the 12-month prevalence of $\mathrm{MDE}$ and $\mathrm{AD}$ as our two primary outcomes.

\section{Adverse childhood experiences}

We assessed participants' recalled exposure, before 18 years of age, to five categories of ACEs: emotional abuse, physical abuse, sexual abuse, household alcohol or substance abuse, and parental divorce or separation. We determined these exposures using MIDUS survey items that had wording similar to items used in the ACE module of the Behavioral Risk Factor Surveillance System (BRFSS) (Table S1) [54]. We did not assess the other three categories of ACEs in the BRFSS module (mental illness in the household, intimate partner violence, and incarcerated household member) because the MIDUS surveys did not contain similarly worded items. An ACE score was created by counting the number of categories of exposure (range 0-5). To facilitate clinical interpretation of our data and allow us to assess any non-linear relationship between the ACE score and MDE or AD, we analyzed the ACE score as a categorical variable with 4 levels: $0,1,2$, and 3-5 categories of exposure to ACEs.

\section{Gender}

During the MIDUS recruitment phone screener, the available household member identified each of the other household members as either female or male, before a respondent was selected from each household to participate. The designation of female or male was confirmed with participants in subsequent surveys. However, sex assigned at birth and gender identity were not assessed separately $[55,56]$. For brevity, we labeled this variable as "gender" rather than "gender-sex" and use the designations "female" and "male" that were the binary designations used with respondents during data collection. In selecting these terms, however, we mean to convey our understanding that the plausible causal mechanisms leading to $\mathrm{MDE}$ and $\mathrm{AD}$, as discussed above, involve both gender and sex and cannot be easily separated in research on humans.

\section{Covariates}

We included four covariates in our analyses which were potential confounders: age, race (self-reported as White, Black, other), childhood socioeconomic disadvantage (SED), and current SED. We created the childhood SED score (range 0 to 6) [57-60] and a current SED score (range 0 to 8) [59], with higher scores reflecting greater SED (see Supplementary Appendix for a detailed description).

\section{Statistical analysis}

Our analysis was restricted to the 4346 participants who returned the SAQ because it included the items needed to construct the ACE score. Two additional participants with missing items for the score were excluded, leaving $4344(74.5 \%)$ for analysis. We applied the poststratification weights developed by the MIDUS research team for participants who returned the SAQ. The weights aligned the distribution of the SAQ participants with the Current Population Survey of the US Census Bureau in terms of gender, race, age, education, and marital status. We used a significance threshold of $P<.05$ from 2 -sided testing.

Logistic regression models were run separately for MDE and AD outcomes. Each model included variables for the ACE score (as 4 levels) and gender (male/female) along with the covariates. In models with all participants, we first estimated the independent associations of the ACE score and gender with each outcome. We then ran these regression models separately for males and females.

We evaluated additive interaction between the risk factors of ACEs and gender by following the recommendations outlined in the Strengthening the Reporting of Observational Studies in Epidemiology (STROBE) statement [42] and employing the method suggested by Knol 
and VanderWeele [34]. We first used regression-based margins, standardized to the distribution of covariates in the study population, to estimate covariate-adjusted (or standardized) prevalences (95\% CI) of MDE and $\mathrm{AD}$ for each of the eight groups defined by gender and level of exposure to ACEs [61].

We then examined how the joint association of the two risk factors (assessed here as the adjusted prevalence of the mental health outcome associated with having both risk factors) differed from the sum of the separate associations of each risk factor in the absence of the other risk factor. We considered there to be evidence of socio-biologic synergy between ACEs and gender if there was a departure from the additive associations of the two risk factors [33]. This was determined by an interaction contrast value $>0$ with a $95 \%$ confidence interval (CI) excluding 0 . The interaction contrast was calculated as the difference between the adjusted prevalence (probability) of the outcome (MDE or AD) for those with both risk factors (i.e., females with a given level of ACEs $\left.\left[\mathrm{P}_{11}\right]\right)$ and the expected prevalence. The expected prevalence was calculated as the sum of the adjusted prevalences associated with each separate risk factor $\left(\mathrm{P}_{10}+\right.$ $\mathrm{P}_{01}$ ) minus the adjusted prevalence associated with having neither risk factor (i.e., males with no ACEs $\left[\mathrm{P}_{00}\right]$ ). In secondary analyses, the same analytic approach was used to examine synergy between gender and the five specific ACEs rather than the ACE score. We also tested for departure from multiplicative associations using the Wald test to examine model fit after adding interaction terms to the logistic models.

\section{Results}

Of the 4344 included in the analysis, $53.9 \%$ were female, 85.1\% were White. At the time of data collection for each cohort, those included in the analysis ranged in age from 25 to 84 years, and their mean (SD) age was 54.1 (13.8) years (Table 1$)$. Those excluded due to missing responses $(n=1490)$ tended to be younger, less educated, and more often male (Table S2). The 12-month prevalences of MDE and AD were 13.7 and $10.0 \%$, respectively, in our analytic sample, which were similar to the prevalences among those not included in the analysis (Table S2).

In our analytic sample, MDE and $\mathrm{AD}$ were more common in females. Among those with AD, 54.2\% reported MDE; among those with MDE, 39.2\% reported AD (Table S3). The prevalences of exposure to $0,1,2,3,4$, and 5 categories of ACEs were 42.7, 26.6, 18.2, 8.9, 3.3, and $0.3 \%$, respectively. The distribution of ACE scores was not significantly different between males and females, with $56.7 \%$ of males and $57.8 \%$ of females reporting exposure to one or more categories of ACEs. However, childhood sexual abuse was reported more often by females (9.6\% vs. $2.3 \%)$ and physical abuse more often by males (23.6\% vs $18.5 \%$ ) (Table S4). Among those reporting exposure to a given ACE, the majority reported experiencing another category of ACE. For example, another category of exposure to ACEs was reported by $80.9 \%$ of those reporting sexual abuse and $85.4 \%$ of those reporting physical abuse.

\section{Association of ACEs and gender with depression and anxiety disorders}

In covariate-adjusted logistic regression models containing gender and ACE score, both risk factors were significantly associated with MDE and AD (Table 2). Compared to males, the adjusted odds of females experiencing $\mathrm{MDE}$ and $\mathrm{AD}$ in the prior 12 months were 2.24 (95\% CI: 1.74, 2.87) and 2.40 (95\% CI: 1.79, 3.22), respectively. There was also a graded association between the ACE score and adjusted odds of MDE and AD. These graded associations between the ACE score and both MDE and AD were stronger for females than males (Table 3). For example, the adjusted odds of MDE associated with reporting 3-5 categories of ACEs (compared to none) were 2.71 (95\% CI: $1.80,4.08)$ for females and 1.76 (95\% CI: 0.96, 3.23) for males. Similarly, the adjusted odds of $\mathrm{AD}$ associated with reporting 3-5 categories of ACEs were 3.92 (95\% CI: 2.48, 6.20) for females and 1.73 (95\% CI: 0.78, 3.83) for males.

\section{Interaction between gender and ACEs}

For both MDE and AD, there was evidence of significant additive interaction between the risk factors of gender (being female) and exposure to ACEs (Fig. 1 and Table 4). For example, the adjusted prevalence of MDE was $26.9 \%$ among females with 3-5 ACEs. This adjusted prevalence represents the joint association of the two risk factors (being female and 3-5 ACEs) on MDE. This was $10.2 \%$ (95\% CI: $1.8,18.5 \%$ ) higher than the prevalence that would be expected based on the sum of the associations of the two risk factors considered separately - the interaction contrast ( $95 \% \mathrm{CI}$ ) shown in Table 4. The adjusted prevalence of MDE for females with 2 ACEs was $24.6 \%$, which was $9.8 \%$ (95\% CI: 2.8 , $16.7 \%$ ) higher than the sum of the separate associations of the risk factors. For the outcome of $\mathrm{AD}$, the adjusted prevalences for females with 3-5 ACEs and 2 ACEs were 21.9 and $17.6 \%$, respectively, which were $11.4 \%$ (95\% CI: $4.0,18.9 \%)$ and $7.2 \%$ (95\% CI: $1.4,12.9 \%)$ higher, respectively, than the sum of the separate associations. When the three interaction terms for gender $(0=M$ and $1=\mathrm{F}$ ) by ACE score (categories of $0,1,2,3-5$ ) were added as a group to models with gender, ACE score, and the covariates, the addition of these interaction terms significantly improved the prediction of the outcomes of MDE and AD in the additive model $(P=.011$ and $P=$ 
Table 1 Participant Characteristics

\begin{tabular}{|c|c|c|c|c|c|c|c|}
\hline \multirow[b]{2}{*}{ Characteristic $^{\mathrm{a}}$} & \multicolumn{2}{|c|}{ All $(N=4344)$} & \multicolumn{2}{|c|}{ Males $(n=2009)$} & \multicolumn{2}{|c|}{ Females $(n=2335)$} & \multirow[b]{2}{*}{$P$ Value $^{\mathrm{b}}$} \\
\hline & No. & $\%(95 \% \mathrm{Cl})^{\mathrm{a}}$ & No. & $\%(95 \% \mathrm{Cl})^{\mathrm{a}}$ & No. & $\%(95 \% \mathrm{Cl})^{\mathrm{a}}$ & \\
\hline \multicolumn{8}{|l|}{ Age, years ${ }^{c}$} \\
\hline$<30$ & 130 & $4.5(3.7,5.5)$ & 63 & $5.7(4.3,7.7)$ & 67 & $3.4(2.6,4.5)$ & \\
\hline $30-39$ & 633 & $17.1(15.8,18.6)$ & 282 & $15.9(14.0,18.1)$ & 351 & $18.2(16.3,20.2)$ & \\
\hline $40-49$ & 882 & $23.9(22.4,25.4)$ & 403 & $24.2(21.9,26.7)$ & 479 & $23.6(21.6,25.6)$ & .054 \\
\hline $50-59$ & 1003 & $24.6(23.1,26.1)$ & 452 & $24.4(22.2,26.7)$ & 551 & $24.7(22.9,26.7)$ & \\
\hline $60-69$ & 1013 & $18.3(17.1,19.5)$ & 485 & $18.3(16.6,20.1)$ & 528 & $18.3(16.7,19.9)$ & \\
\hline$\geq 70$ & 683 & $11.7(10.7,12.7)$ & 324 & $11.5(10.2,13.0)$ & 359 & $11.8(10.6,13.2)$ & \\
\hline \multicolumn{8}{|l|}{ Race } \\
\hline White & 3745 & $85.1(83.7,86.3)$ & 1779 & $86.2(84.0,88.1)$ & 1966 & $84.1(82.4,85.7)$ & .070 \\
\hline Black & 250 & $6.9(5.9,8.0)$ & 76 & $5.6(4.2,7.5)$ & 174 & $8.0(6.8,9.3)$ & \\
\hline Other & 325 & $8.0(7.2,9.0)$ & 146 & $8.2(6.8,9.7)$ & 179 & $8.0(6.8,9.3)$ & \\
\hline \multicolumn{8}{|c|}{ Current SED score $^{d}$} \\
\hline $0-1$ & 809 & $13.5(12.6,14.5)$ & 449 & $15.1(13.7,16.7)$ & 360 & $12.1(10.9,13.5)$ & \\
\hline $2-3$ & 1257 & $25.5(24.1,26.9)$ & 611 & $25.6(23.6,27.8)$ & 646 & $25.4(23.6,27.3)$ & .065 \\
\hline $4-5$ & 1298 & $31.5(29.9,33.2)$ & 573 & $31.1(28.7,33.6)$ & 725 & $31.9(29.8,34.1)$ & \\
\hline $6-8$ & 940 & $29.5(27.7,31.3)$ & 356 & $28.2(25.4,31.0)$ & 584 & $30.6(28.4,32.9)$ & \\
\hline \multicolumn{8}{|c|}{ Childhood SED score $^{e}$} \\
\hline 0 & 853 & $17.9(16.7,19.2)$ & 421 & $18.8(17.0,20.9)$ & 432 & $17.2(15.6,18.9)$ & \\
\hline 1 & 999 & $21.8(20.4,23.2)$ & 467 & $21.8(19.7,24.0)$ & 532 & $21.7(19.9,23.6)$ & .729 \\
\hline 2 & 1165 & $28.0(26.4,29.6)$ & 525 & $27.5(25.2,30.0)$ & 640 & $28.3(26.3,30.4)$ & \\
\hline 3 & 831 & $20.2(18.8,21.7)$ & 379 & $20.3(18.2,22.6)$ & 452 & $20.2(18.4,22.1)$ & \\
\hline $4-6$ & 489 & $12.1(11.0,13.3)$ & 213 & $11.6(9.9,13.4)$ & 276 & $12.6(11.1,14.2)$ & \\
\hline \multicolumn{8}{|l|}{ ACE score ${ }^{f}$} \\
\hline 0 & 1955 & $42.7(41.0,44.4)$ & 946 & $43.3(40.7,45.9)$ & 1009 & $42.2(40.0,44.5)$ & \\
\hline 1 & 1141 & $26.6(25.0,28.2)$ & 515 & $26.6(24.3,29.1)$ & 626 & $26.5(24.6,28.6)$ & .542 \\
\hline 2 & 768 & $18.2(16.9,19.6)$ & 351 & $18.5(16.5,20.7)$ & 417 & $17.9(16.2,19.7)$ & \\
\hline $3-5$ & 480 & $12.5(11.4,13.8)$ & 197 & $11.6(9.9,13.5)$ & 283 & $13.3(11.8,15.1)$ & \\
\hline \multicolumn{8}{|c|}{ Major depressive episode } \\
\hline Yes & 521 & $13.7(12.5,15.0)$ & 156 & $9.0(7.5,10.8)$ & 365 & $17.8(16.0,19.7)$ & \\
\hline No & 3823 & $86.3(85.0,87.5)$ & 1853 & $91.0(89.2,92.5)$ & 1970 & $82.2(80.3,84.0)$ & $<.001$ \\
\hline \multicolumn{8}{|l|}{ Anxiety disorder } \\
\hline Yes & 372 & $10.0(8.9,11.1)$ & 97 & $6.1(4.8,7.7)$ & 275 & $13.2(11.7,14.9)$ & \\
\hline No & 3972 & $90.0(88.9,91.1)$ & 1912 & $93.9(92.3,95.2)$ & 2060 & $86.8(85.1,88.3)$ & $<.001$ \\
\hline
\end{tabular}

Note: $\mathrm{SED}=$ socioeconomic disadvantage, $\mathrm{ACE}=$ adverse childhood experience; MIDUS = Midlife in the United States study

${ }^{a}$ No. and $\%(95 \% \mathrm{Cl})=$ unweighted $\mathrm{n}$ and weighted percentages $(95 \% \mathrm{Cl})$ of sample. Percentages may not add to 100 due to rounding. Participants were missing data on covariates as follows: race ( 24 cases, 8 males and 16 females), childhood socioeconomic disadvantage score (7 cases, 4 males and 3 females), and current socioeconomic disadvantage score (40 cases, 20 males and 20 females)

${ }^{\mathrm{b}} P$ value is for chi-square test assessing differences between males and females in the weighted proportion of participants at each level of a participant characteristic

'The combined sample mean (SD) = 54.1 (13.8) years

${ }^{\mathrm{d}}$ Score based on 4 variables (highest level of education, perceived financial situation, enough money to meet needs, and difficulty paying monthly bills). Higher score (possible range $0-8$ ) is more disadvantage

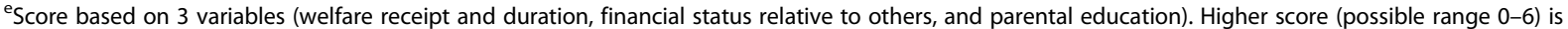
more disadvantage

${ }^{f}$ Score based on exposure to 5 categories of adverse childhood experiences (emotional abuse, physical abuse, sexual abuse, parental separation or divorce, and household alcohol or substance abuse) 
Table 2 Odds of Major Depressive Episode and Anxiety Disorder Associated with Two Risk Factors: Adverse Childhood Experience Score and Gender

\begin{tabular}{|c|c|c|c|c|}
\hline \multirow[b]{2}{*}{ Risk Factor } & \multirow{2}{*}{$\begin{array}{l}\text { Prevalence } \\
\text { of } \\
\text { Disorder, } \\
\text { Proportion } \\
(\%)^{\mathrm{a}}\end{array}$} & \multirow{2}{*}{$\begin{array}{l}\text { Model } 1^{\mathrm{b}} \\
\text { Odds Ratio } \\
(95 \% \mathrm{Cl})\end{array}$} & \multicolumn{2}{|c|}{ Model $2^{c}$} \\
\hline & & & $\begin{array}{l}\text { Odds Ratio } \\
(95 \% \mathrm{Cl})\end{array}$ & $P$ Value $^{\mathrm{d}}$ \\
\hline
\end{tabular}

Major Depressive Episode ${ }^{\mathrm{e}}$

ACE score

$\begin{array}{llll}0 & \begin{array}{llll}158 / 1955 \\ (9.2)\end{array} & \text { Reference } & \text { Reference } \\ & & & \\ 1 & 120 / 1141 & 1.30 & 1.16 \\ & (11.7) & (0.97,1.74) & (0.86,1.57) \\ 2 & 129 / 768 & 2.38 & 2.01 \\ & (19.2) & (1.79,3.18) & (1.49,2.72) \\ 3-5 & 114 / 480 & 3.34 & 2.34 \\ & (25.5) & (2.45,4.56) & (1.67,3.28)\end{array}$

Gender

$\begin{array}{llll}\text { Males } & \begin{array}{l}156 / 2009 \\ (9.0)\end{array} & \text { Reference } & \text { Reference } \\ \text { Females } & \begin{array}{l}365 / 2335 \\ \text { (17.8) }\end{array} & 2.18 & \\ & (1.72,2.78) & (1.74,2.87)\end{array}$

Anxiety Disorder ${ }^{\mathrm{f}}$

ACE score

$0 \quad 95 / 19$

$1 \quad 89 / 1141$

(9.6)

$2 \quad 101 / 768$

(13.8)

$3-5 \quad 87 / 480$

(20.3)

$(1.72,2.78)$

$(1.74,2.87)$

$<.001$

(n)

$r^{f}$

Reference Reference

$\begin{array}{ll}1.84 & 1.70 \\ (1.30,2.61) & (1.19,2.44) \\ 2.82 & 2.45 \\ (2.01,3.95) & (1.72,3.49) \\ 4.38 & 3.05 \\ (3.05,6.27) & (2.06,4.51)\end{array}$

Gender

$\begin{array}{llll}\text { Males } & \begin{array}{l}97 / 2009 \\ (6.1)\end{array} & \text { Reference } & \text { Reference } \\ \text { Females } & \begin{array}{l}275 / 2335 \\ (13.2)\end{array} & 2.33 & 2.40 \\ & (1.74,3.11) & (1.79,3.22)\end{array}$

aPrevalence is unadjusted. Proportion $=$ number with the mental health disorder/ number in the group defined by adverse childhood experience (ACE) score (count of 5 categories of exposure to ACEs as 4 levels) or gender (male or female). All numbers unweighted. Percentage $=$ weighted 12 -month prevalence of major depressive episode or anxiety disorder

${ }^{\mathrm{b}}$ Model 1 is logistic regression model with the mental health disorder (major depressive episode or anxiety disorder) as the dependent variable and ACE score (as 4 levels) and gender as independent variables $(N=4344)$

${ }^{\mathrm{C}}$ Model 2 is logistic regression model with the mental health disorder (major depressive episode or anxiety disorder) as the dependent variable and ACE score, gender, and 4 covariates (age, race, childhood socioeconomic disadvantage [SED] and current SED) as independent variables. $N=4275$ after a listwise deletion of 69 participants (31 males and 38 females), who were missing data on race, childhood SED, or current SED

${ }^{\mathrm{d}} P$ value for the Wald test, which was used to assess whether the addition of the ACE score or gender significantly improved the model fit over a model with 4 covariates and the other risk factor (ACE score or gender)

eWald test was used to assess the addition of three gender $x$ ACE interaction terms to Model 2: $F(3,4272)=1.22 ; P=.302$ (assessing interaction in a multiplicative model)

fWald test was used to assess the addition of three gender $x$ ACE interaction terms to Model 2: $F(3,4272)=1.17 ; P=.318$ (assessing interaction in a multiplicative model)
.004 , respectively) but not in the multiplicative (logistic) model $(P=.302$ and $P=.318$, respectively). Evidence for synergy was also found when we re-examined the data three ways: unweighted, separately for those in each cohort, and without adjusting for current SED.

In secondary analyses, the associations of the five specific ACEs with MDE and AD (Tables S5 and S6) were similar to the analogous associations we found with the ACE score, with some exceptions. We also found significant additive interactions between gender and specific ACEs (Figs. S1 and S2 and Table S7).

\section{Discussion}

In a cross-sectional analysis of survey data from US adults, we found that exposure to ACEs and being female are synergistic risk factors for a current MDE or an $\mathrm{AD}$. This means that the risk associated with the combination of these two factors is greater than the sum of the independent risks. For example, the prevalence of $\mathrm{AD}$ among females with 3-5 ACEs was more than twice as high as the expected prevalence (21.9\% vs. $10.5 \%)$ based on the sum of the two separate risk factors. Synergy also means that exposure to ACEs poses a greater risk for depression and anxiety in females than in males. If over one-third of all cases of adult depression and anxiety disorders are due to ACEs [43], then this proportion is even greater for females.

\section{Research in context}

Other population-based studies have not demonstrated a significant interaction between ACEs and gender as risk factors for adult depression and anxiety disorders [36, 38-41]. However, these studies may not have detected synergy between the two risk factors because the investigators tested for departure from multiplicative associations rather than from additive associations, as we did [33]. These studies did not document the separate associations of the two risk factors and their joint association using one reference category [42], so it is not possible to evaluate whether the data from these studies, like our own, showed evidence of significant departure from additive associations (synergy) without a significant departure from multiplicative associations. Chapman and colleagues, using data from 9460 members of the San Diego (CA) Kaiser Permanente health plan participating in the Adverse Childhood Experiences Study, reported the association between the ACE score (0-7) and current depression separately by gender [37]. The unadjusted prevalence data in that report suggest synergy between exposure to ACEs and being female, but interaction was not formally tested. Afifi and colleagues, using data from 5692 participants in the 2001-2003 US National Comorbidity Survey Replication, also stratified 
Table 3 Odds of Major Depressive Episode and Anxiety Disorder Associated with Adverse Childhood Experience Score, Stratified by Gender

\begin{tabular}{|c|c|c|c|c|}
\hline \multirow[b]{2}{*}{ Risk Factor } & \multirow{2}{*}{$\begin{array}{l}\text { Prevalence } \\
\text { of } \\
\text { Disorder, } \\
\text { Proportion } \\
(\%)^{\mathrm{a}}\end{array}$} & \multirow{2}{*}{$\begin{array}{l}\text { Model } 1^{\text {b }} \\
\text { Odds Ratio } \\
(95 \% \mathrm{Cl})\end{array}$} & \multicolumn{2}{|c|}{ Model $2^{c}$} \\
\hline & & & $\begin{array}{l}\text { Odds Ratio } \\
(95 \% \mathrm{Cl})\end{array}$ & $P$ Value $^{\mathrm{d}}$ \\
\hline
\end{tabular}

MDE -- Males

ACE score$$
55 / 946
$$$$
1 \quad 38 / 515
$$$$
\text { (8.1) }
$$$$
234 / 351
$$$$
\text { (11.4) }
$$$$
\text { 3-5 29/197 }
$$$$
\text { (15.2) }
$$

$5 / 946$
$6.9)$
$38 / 515$
$(8.1)$
$3 / 351$
$(11.4)$
$29 / 197$
$(15.2)$

$$
\begin{array}{ll}
\text { Reference } & \text { Reference } \\
1.20 & 1.02 \\
(0.70,2.04) & (0.59,1.77) \\
1.74 & 1.38 \\
(1.02,2.98) & (0.78,2.44) \\
2.42 & 1.76 \\
(1.37,4.28) & (0.96,3.23)
\end{array}
$$

MDE -- Females

$\begin{array}{clll}\text { ACE score } & & & \\ 0 & \begin{array}{l}103 / 1009 \\ (11.3)\end{array} & \text { Reference } & \text { Reference } \\ 1 & \begin{array}{l} \\ 0\end{array} & 1.36 & \\ & (14.7) & (0.96,1.91) & (0.86,1.79) \\ 2 & 95 / 417 & 2.79 & 2.44 \\ & (26.2) & (1.98,3.93) & (1.70,3.49) \\ 3-5 & 85 / 283 & 3.91 & 2.71 \\ & (33.2) & (2.69,5.69) & (1.80,4.08)\end{array}$

\section{AD -- Males}

ACE score

$\begin{array}{llll}0 & \begin{array}{l}32 / 946 \\ (4.2)\end{array} & \text { Reference } & \text { Reference } \\ 1 & 23 / 515 & 1.41 & 1.25 \\ & (5.9) & (0.72,2.76) & (0.63,2.47) \\ 2 & 26 / 351 & 2.04 & 1.79 \\ & (8.3) & (1.09,3.84) & (0.94,3.41) \\ 3-5 & 16 / 197 & 2.54 & 1.73 \\ & (10.1) & (1.20,5.34) & (0.78,3.83)\end{array}$

AD -- Females

$\begin{array}{cllll}\text { ACE score } & & & & \\ 0 & 63 / 1009 & \text { Reference } & \text { Reference } & \\ & (6.5) & & & \\ 1 & 66 / 626 & 2.10 & 1.98 & \\ & (12.8) & (1.41,3.14) & (1.31,3.01) & \\ 2 & 75 / 417 & 3.30 & 2.89 & <.001 \\ & (18.7) & (2.22,4.88) & (1.90,4.39) & \\ 3-5 & 71 / 283 & 5.56 & 3.92 & \\ & (27.9) & (3.67,8.42) & (2.48,6.20) & \\ & & & & \end{array}$

${ }^{\text {a }}$ Prevalence is unadjusted. Proportion = number with the mental health disorder/ number in the group defined by adverse childhood experience (ACE) score (count of 5 categories of exposure to ACEs as 4 levels). All numbers unweighted. Percentage $=$ weighted 12 -month prevalence of major depressive episode or anxiety disorder

${ }^{b}$ Model 1 is logistic regression model with the mental health disorder (major depressive episode or anxiety disorder) as the dependent variable and ACE score (as 4 levels) as the independent variable. For males, $N=2009$ and for females $N=2335$

${ }^{c}$ Model 2 is logistic regression model with the mental health disorder (major depressive episode or anxiety disorder) as the dependent variable and ACE score and 4 covariates (age, race, childhood socioeconomic disadvantage [SED] and current SED) as independent variables. For males, $N=1978$ after a listwise deletion of 31 participants who were missing data on race, childhood SED, or current SED. For females, $N=2297$ after a listwise deletion of 38 participants who were missing data on race, childhood SED, or current SED

${ }^{\mathrm{d}} P$ value for the Wald test, which was used to assess whether the addition of the ACE score significantly improved the model fit over a model with 4 covariates

their analyses by gender but not in a manner that permitted evaluation of possible synergy [35].

\section{Limitations}

From this single, cross-sectional study we cannot make causal inferences about the association between ACEs and mental health. However, the aggregate evidence from many studies of varying designs suggests that exposure to ACEs and being female are each distinct causal risk factors for adult depression or anxiety disorders. Recall bias, common-rater bias, and residual confounding are limitations of a cross-sectional design. Recall bias, in particular, is a well-studied methodological challenge when examining the association of ACEs and mental health in populations [62, 63]. This challenge arises, in part, from the inherent subjectivity of one's experience of adverse events, particularly those that occur in childhood. However, we are not aware of evidence that recall bias affects males and females to a different degree [64] or in a manner that would alter our conclusions about synergy between exposure to ACEs and being female.

Apart from recall bias, misclassification bias could have resulted from assessing only five categories ACEs. There are known limitations of the most widely used measure of ACEs [65], which includes the 10 categories of exposure used in the Adverse Childhood Experiences Study [66] and later implemented in BRFSS [54]. For example, some have suggested expanding the list of ACEs to include measures of childhood exposure to socioeconomic deprivation and inequity [67], which we analyzed as a potential confounder. However, we are not aware of any evidence that other approaches to generating an ACEs score would have altered our findings about synergy between exposure to ACEs and being female. Using categories of ACEs that were part of the original ACE score increased the comparability of our findings to other studies that examined the interaction between ACEs and gender as risk factors for adult depression and 


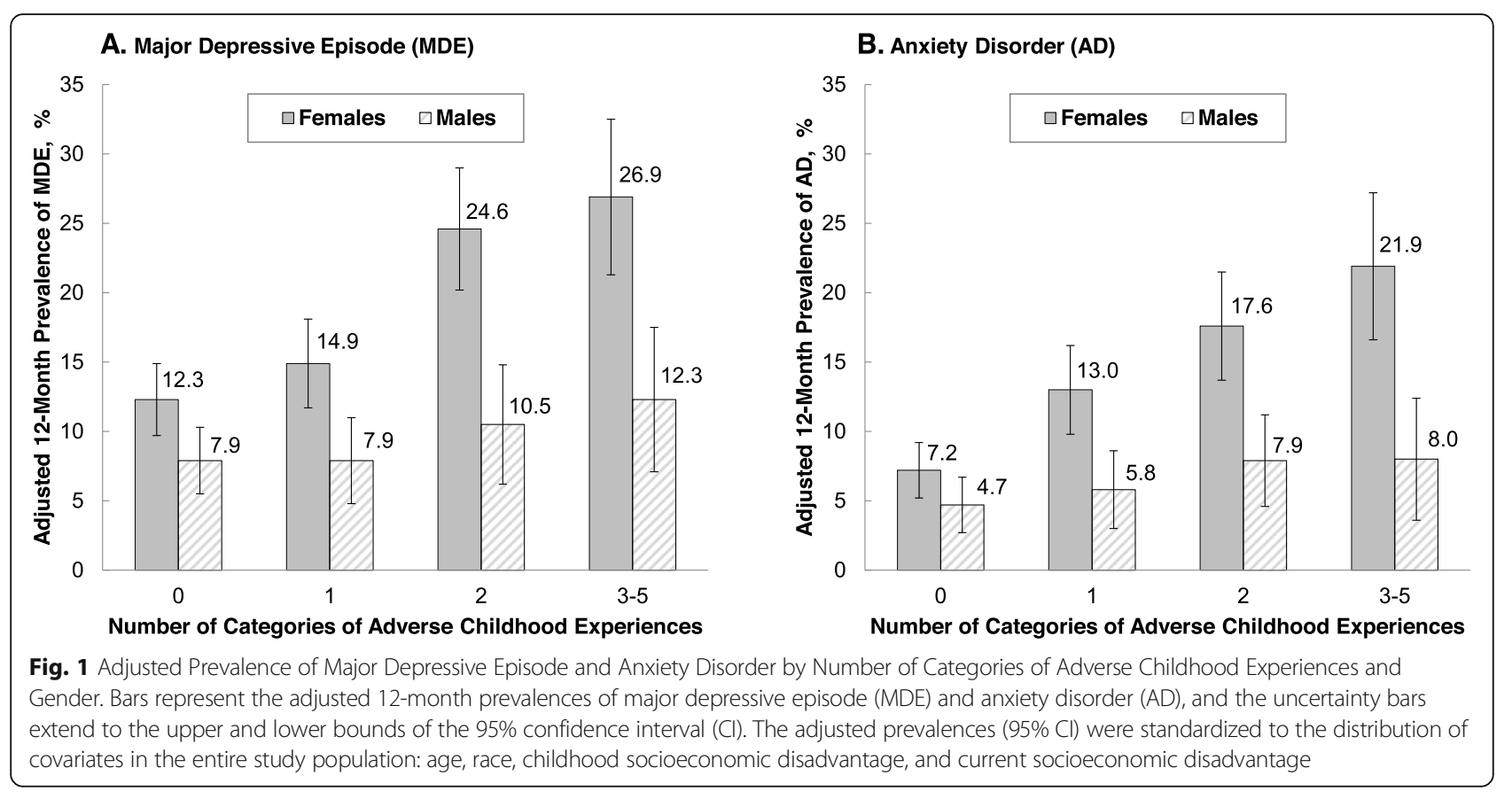

anxiety disorders [36, 38-41]. In addition, by limiting the ACE score to the five categories of ACEs that were assessed in MIDUS with wording similar to BRFSS, we were able to show that the level of ACE exposure in the MIDUS sample was comparable to that in BRFSS (Table S2).

Misclassification bias may have also resulted in assessing the outcome, because we used the CIDI-SF, which is an abbreviated assessment based on DSM-IV diagnostic criteria [68]. Gender and sex were not measured as separate constructs, which may conflate putative causal mechanisms. However, this epidemiologic study was designed to evaluate the presence of synergy between exposure to ACEs and being female and not to determine the mechanisms. Finally, our use of sampling weights permit inference to the US population but use of the weights generally increases variance estimates and does not assure generalizability.

\section{Implications for research and practice}

The scientific and social contexts that inform our understanding of ACEs [65, 67, 69], gender [70], and depression and anxiety $[71,72]$ are all changing rapidly, and these changes will continue to alter how these constructs are measured in research and practice. Researchers and clinicians should focus not only on how ACEs, even as traditionally assessed, interact with gender, but also how ACEs interact with other socially-determined constructs, such as race, which can cause trauma [29, 30, 73]. Additionally, future research should collect data on experiences of sexism to better understand the mechanisms linking gender, ACEs, and mental health.
The effectiveness of treating depression and anxiety disorders in girls and women might be improved by treatments that address the joint impacts of developmental trauma and sexism. Although our study did not include data on sexism, our findings on synergy are consistent with the possibility that the stresses of sexism can be reinforced, exacerbated, or amplified by other childhood traumas in a way that makes the risk of these traumas and being female more than additive. Therefore, treatments for depression and anxiety disorders in girls and women may be unsuccessful if they focus only or primarily on symptom management, with either medications or behavioral therapy. Broader training is needed in psychology, social work, and psychiatry on treatments that address the underlying and synergistic interaction between ACEs and gender, including sexism [74].

Addressing rigid gender norms and sexism may benefit the health of the entire population. For girls and women, reducing the harmful effects of sexism on psychophysiology might prevent the added exposure to ACEs from resulting in depression and anxiety disorders. Regardless of one's gender identity, rigid gender norms can place harmful constraints on emotional expression, behavior, and social roles, which can negatively impact mental health [28]. Finally, the mental health consequences of potentially traumatic experiences can be worsened by gender stereotypes that determine and constrain the "acceptable" ways of managing those experiences [75].

In conclusion, this study, conducted using data collected in a nationally-representative sample of US adults, provides evidence that ACEs and being female are 


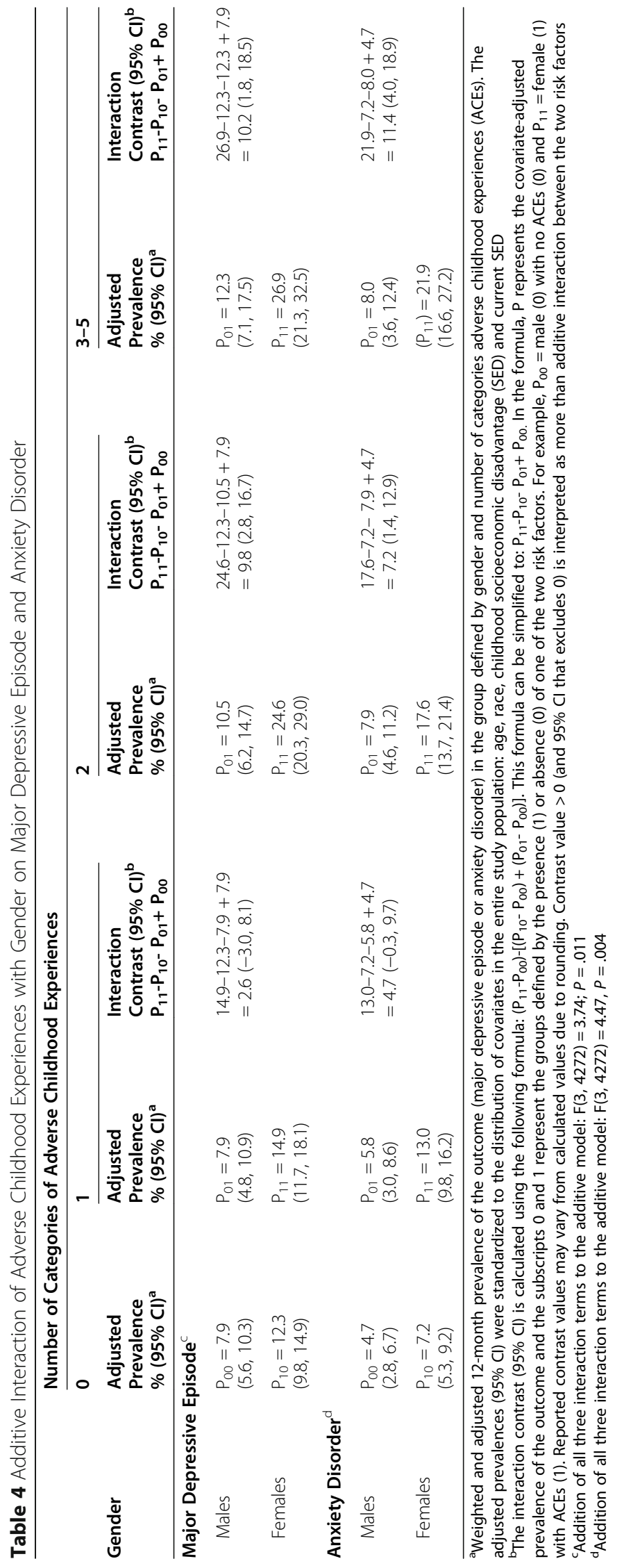


synergistic (more than additive) risk factors for depression and anxiety disorders. Beyond ongoing efforts to prevent ACEs, this study points to the potential to improve the prevention and treatment of these common mental health disorders by addressing sexism as a potentially modifiable traumatic experience. Preventing sexism will require a recognition that it can occur alongside other types of discrimination, such as racism, with which it interacts [76] and which are also transmitted socially across generations [77].

\section{Supplementary Information}

The online version contains supplementary material available at https://doi. org/10.1186/s12889-021-12058-z.

Additional file 1. Supplementary Appendix.

\section{Acknowledgements}

We would like to thank Richard MacLehose, PhD (University of Minnesota, School of Public Health) for his advice regarding data analysis.

\section{Authors' contributions}

RCW conceptualized the study, participated in data analysis and interpretation, and drafted the manuscript. TDW participated in study conceptualization, analyzed the data, participated in data interpretation, and substantively revised the manuscript. ANH participated in study conceptualization, participated in data interpretation, and substantively revised the manuscript. $\mathrm{AEB}, \mathrm{MHH}$, and NAW participated in study conceptualization and substantively revised the manuscript. JMO participated in data analysis and interpretation. All authors have read and approved the final manuscript.

\section{Funding}

There was no external funding to support this work. Publicly-available data from the MIDUS study were used for this research. Since 1995, the MIDUS study has been funded by the following: John D. and Catherine T. MacArthur Foundation Research Network, National Institute on Aging (P01-AG020166) and National Institute on Aging (U19-AG051426).

\section{Availability of data and materials}

The data that support the findings of this study are openly available at the Inter-University Consortium for Political and Social Research: MIDUS I data at https://doi.org/10.3886/ICPSR02760.v18; MIDUS II at https://doi.org/10.3886/ ICPSR04652.v7; and MIDUS Refresher at https://doi.org/10.3886/ICPSR36532.v3.

\section{Declarations}

\section{Ethics approval and consent to participate}

Because the Midlife in the United States (MIDUS) data we used were deidentified and publicly available (see availability of data and materials), our study did not require institutional review board approval.

\section{Consent for publication}

Not applicable.

\section{Competing interests}

The authors declare that they have no competing interests.

\section{Author details}

${ }^{1}$ Columbia-Bassett Program, Vagelos College of Physicians and Surgeons, Columbia University, New York, NY, USA. ${ }^{2}$ Columbia-Bassett Program, Bassett Medical Center, Cooperstown, NY, USA. ${ }^{3}$ Bassett Research Institute, Bassett Medical Center, Cooperstown, NY, USA. ${ }^{4}$ Department of Pediatrics, Vagelos College of Physicians and Surgeons, Columbia University, New York, NY, USA. ${ }^{5}$ Division of Epidemiology and Community Health, School of Public Health, University of Minnesota, Minneapolis, MN, USA.
Received: 28 May 2021 Accepted: 18 October 2021

Published online: 12 November 2021

\section{References}

1. Merrick MT, Ford DC, Ports KA, Guinn AS. Prevalence of adverse childhood experiences from the 2011-2014 Behavioral Risk Factor Surveillance System in 23 states. JAMA Pediatr. 2018;172(11):1038-44. https://doi.org/10.1001/ja mapediatrics.2018.2537.

2. Gardner $\mathrm{M}$, Thomas $\mathrm{H}$, Erskine $H$. The association between five forms of child maltreatment and depressive and anxiety disorders: a systematic review and meta-analysis. Child Abuse Negl. 2019;96:104082. https://doi. org/10.1016/j.chiabu.2019.104082.

3. Teicher $\mathrm{MH}$, Samson JA. Annual research review: enduring neurobiological effects of childhood abuse and neglect. J Child Psychol Psychiatry. 2016; 57(3):241-66. https://doi.org/10.1111/jcpp.12507.

4. Danese A, McEwen BS. Adverse childhood experiences, allostasis, allostatic load, and age-related disease. Physiol Behav. 2012;106(1):29-39. https://doi. org/10.1016/j.physbeh.2011.08.019.

5. D'Andrea W, Ford J, Stolbach B, Spinazzola J, van der Kolk BA. Understanding interpersonal trauma in children: why we need a developmentally appropriate trauma diagnosis. Am J Orthopsychiatry. 2012; 82(2):187-200. https://doi.org/10.1111/j.1939-0025.2012.01154.x

6. Sroufe LA, Egeland B, Carlson EA, Collins WA. The development of the person: the Minnesota study of risk and adaptation from birth to adulthood. New York, NY: Guilford Press; 2005.

7. Gater R, Tansella M, Korten A, Tiemens BG, Mavreas VG, Olatawura MO. Sex differences in the prevalence and detection of depressive and anxiety disorders in general health care settings: report from the World Health Organization collaborative study on psychological problems in general health care. Arch Gen Psychiatry. 1998;55(5):405-13. https://doi.org/10.1 001/archpsyc.55.5.405

8. Weissman MM, Bland RC, Canino GJ, Faravelli C, Greenwald S, Hwu HG, et al. Cross-national epidemiology of major depression and bipolar disorder. JAMA 1996;276(4):293-9. https://doi.org/10.1001/jama.1996.03540040037030.

9. Kessler RC, McGonagle KA, Zhao S, Nelson CB, Hughes M, Eshleman S, et al. Lifetime and 12-month prevalence of DSM-III-R psychiatric disorders in the United States: results from the National Comorbidity Survey. Arch Gen Psychiatry. 1994;51(1):8-19. https://doi.org/10.1001/archpsyc.1994.0395001 0008002.

10. Kessler RC, Berglund P, Demler O, Jin R, Merikangas KR, Walters EE. Lifetime prevalence and age-of-onset distributions of DSM-IV disorders in the National Comorbidity Survey Replication. Arch Gen Psychiatry. 2005;62(6): 593-602. https://doi.org/10.1001/archpsyc.62.6.593.

11. Schmitt MT, Branscombe NR, Postmes T, Garcia A. The consequences of perceived discrimination for psychological well-being: a meta-analytic review. Psychol Bull. 2014;140(4):921-48. https://doi.org/10.1037/a003 5754

12. Klonoff EA, Landrine $H$, Campbell R. Sexist discrimination may account for well-known gender differences in psychiatric symptoms. Psychol Women Q. 2000;24(1):93-9. https://doi.org/10.1111/j.1471-6402.2000.tb01025.x.

13. Hackett RA, Steptoe A, Jackson SE. Sex discrimination and mental health in women: a prospective analysis. Health Psychol. 2019;38(11):1014-24. https:// doi.org/10.1037/hea0000796

14. McLean CP, Anderson ER. Brave men and timid women? A review of the gender differences in fear and anxiety. Clin Psychol Rev. 2009;29(6):496-505. https://doi.org/10.1016/j.cpr.2009.05.003.

15. Nolen-Hoeksema S. Emotion regulation and psychopathology: the role of gender. Annu Rev Clin Psychol. 2012;8(1):161-87. https://doi.org/10.1146/a nnurev-clinpsy-032511-143109.

16. Rubinow DR, Schmidt PJ. Sex differences and the neurobiology of affective disorders. Neuropsychopharmacology. 2019;44(1):111-28. https://doi.org/1 0.1038/s41386-018-0148-z.

17. Altemus M, Sarvaiya N, Epperson CN. Sex differences in anxiety and depression clinical perspectives. Front Neuroendocrinol. 2014;35(3):320-30. https://doi.org/10.1016/j.yfrne.2014.05.004.

18. Krieger N. Genders, sexes, and health: what are the connections-and why does it matter? Int J Epidemiol. 2003;32(4):652-7. https://doi.org/10.1093/ije/ dyg 156.

19. Doom JR, Cicchetti D, Rogosch FA, Dackis MN. Child maltreatment and gender interactions as predictors of differential neuroendocrine profiles. 
Psychoneuroendocrinology. 2013;38(8):1442-54. https://doi.org/10.1016/j. psyneuen.2012.12.019.

20. Whittle $S$, Yücel M, Yap MBH, Allen NB. Sex differences in the neural correlates of emotion: evidence from neuroimaging. Biol Psychol. 2011; 87(3):319-33. https://doi.org/10.1016/j.biopsycho.2011.05.003.

21. Baldwin JR, Arseneault $\mathrm{L}$, Caspi A, Fisher HL, Moffitt TE, Odgers $\mathrm{CL}$, et al. Childhood victimization and inflammation in young adulthood: a genetically sensitive cohort study. Brain Behav Immun. 2018;67:211-7. https://doi.org/10.1016/j.bbi.2017.08.025.

22. Goldstein JM, Holsen L, Handa R, Tobet S. Fetal hormonal programming of sex differences in depression: linking women's mental health with sex differences in the brain across the lifespan. Front Neurosci. 2014;8:247. https://doi.org/10.3389/fnins.2014.00247.

23. Heim C, Shugart M, Craighead WE, Nemeroff CB. Neurobiological and psychiatric consequences of child abuse and neglect. Dev Psychobiol. 2010; 52(7):671-90. https://doi.org/10.1002/dev.20494.

24. Ellis BJ, Horn AJ, Carter CS, van ljzendoorn MH, Bakermans-Kranenburg MJ. Developmental programming of oxytocin through variation in early-life stress: four meta-analyses and a theoretical reinterpretation. Clin Psychol Rev. 2021;86:101985. https://doi.org/10.1016/j.cpr.2021.101985.

25. Taylor SE. Tend and befriend: biobehavioral bases of affiliation under stress. Curr Dir Psychol Sci. 2006;15(6):273-7. https://doi.org/10.1111/j.1467-8721.2 006.00451.X.

26. Craske MG. Why more women than men? In: Craske MG, ed. Origins of Phobias and Anxiety Disorders. Why More Women than Men? Oxford: Elsevier Science; 2003:175-203.

27. Lewis JA. From modern sexism to gender microaggressions: understanding contemporary forms of sexism and their influence on diverse women. In: Travis CB, White JW, editors. APA handbook of the psychology of women: history theory, and battlegrounds, vol. 1. Washington, DC, US: American Psychological Association; 2018. p. 381-97. https://doi.org/10.1037/0000059-019.

28. Barlow FK, Vickers-Jones R, Alba B, Williamson E, Hutton V. Sexism. In: Hutton V, Sisko S, eds. Multicultural Responsiveness in Counselling and Psychology: Working with Australian Populations. Springer Nature Switzerland AG; 2021:125-151.

29. Bernard DL, Calhoun CD, Banks DE, Halliday CA, Hughes-Halbert C, Danielson CK. Making the "C-ACE" for a culturally-informed adverse childhood experiences framework to understand the pervasive mental health impact of racism on black youth. J Child Adolesc Trauma. 2021;14(2): 233-47. https://doi.org/10.1007/s40653-020-00319-9.

30. Barajas-Gonzalez RG, Ayón C, Brabeck K, Rojas-Flores L, Valdez CR. An ecological expansion of the adverse childhood experiences (ACES) framework to include threat and deprivation associated with US immigration policies and enforcement practices: an examination of the Latinx immigrant experience. Soc Sci Med. 2021;114126:114126. https://doi. org/10.1016/j.socscimed.2021.114126.

31. Putnam FW, Amaya-Jackson L, Putnam KT, Briggs EC. Synergistic adversities and behavioral problems in traumatized children and adolescents. Child Abuse Negl. 2020;106:104492. https://doi.org/10.1016/ j.chiabu.2020.104492.

32. Putnam KT, Harris WW, Putnam FW. Synergistic childhood adversities and complex adult psychopathology. J Trauma Stress. 2013;26(4):435-42. https:// doi.org/10.1002/jts.21833

33. Greenland S, Lash TL, Rothman KJ. Concepts of interaction. In: Rothman KJ Greenland S, Lash TL, eds. Modern epidemiology. 3rd ed. Philadelphia, PA: Lippincott Williams \& Wilkins; 2008. p. 71-86.

34. Knol MJ, VanderWeele TJ. Recommendations for presenting analyses of effect modification and interaction. Int J Epidemiol. 2012;41(2):514-20. https://doi.org/10.1093/ije/dyr218.

35. Afifi TO, Enns MW, Cox BJ, Asmundson GJ, Stein MB, Sareen J. Population attributable fractions of psychiatric disorders and suicide ideation and attempts associated with adverse childhood experiences. Am J Public Health. 2008;98(5):946-52. https://doi.org/10.2105/AJPH.2 007.120253

36. Arnow BA, Blasey CM, Hunkeler EM, Lee J, Hayward C. Does gender moderate the relationship between childhood maltreatment and adult depression? Child Maltreat. 2011;16(3):175-83. https://doi.org/10.1177/1 077559511412067

37. Chapman DP, Whitfield CL, Felitti VJ, Dube SR, Edwards VJ, Anda RF. Adverse childhood experiences and the risk of depressive disorders in adulthood. J Affect Disord. 2004;82(2):217-25. https://doi.org/10.1016/j.jad.2 003.12.013.

38. Choi NG, DiNitto DM, Marti CN, Choi BY. Association of adverse childhood experiences with lifetime mental and substance use disorders among men and women aged 50+ years. Int Psychogeriatr. 2017;29(3):359-72. https:// doi.org/10.1017/S1041610216001800.

39. Meng X, D'Arcy C. Gender moderates the relationship between childhood abuse and internalizing and substance use disorders later in life: a crosssectional analysis. BMC Psychiatry. 2016;16(1):401. https://doi.org/10.1186/s12 888-016-1071-7.

40. Sunley AK, Lok A, White MJ, Snijder MB, van Zuiden M, Zantvoord JB, et al. Ethnic and sex differences in the association of child maltreatment and depressed mood. The HELIUS study. Child Abuse Negl. 2020;99:104239. https://doi.org/10.1016/j.chiabu.2019.104239.

41. Lee RD, Chen J. Adverse childhood experiences, mental health, and excessive alcohol use: examination of race/ethnicity and sex differences. Child Abuse Negl. 2017;69:40-8. https://doi.org/10.1016/j.chiabu.2017.04.004.

42. Vandenbroucke JP, von Elm E, Altman DG, Gøtzsche PC, Mulrow CD, Pocock SJ, et al. Strengthening the reporting of observational studies in epidemiology (STROBE): explanation and elaboration. PLoS Med. 2007;4(10): e297. https://doi.org/10.1371/journal.pmed.0040297.

43. Bellis MA, Hughes K, Ford K, Rodriguez GR, Sethi D, Passmore J. Life course health consequences and associated annual costs of adverse childhood experiences across Europe and North America: a systematic review and meta-analysis. Lancet Public Health. 2019;4(10):e517-28. https://doi.org/10.1 016/S2468-2667(19)30145-8.

44. Institute on Aging, University of Wisconsin. Midlife in the United States (MIDUS): a national longitudinal study of aging and wellbeing: history \& overview of MIDUS. Madison, WI: Institute on Aging; 2011. http://midus.wisc. edu/scopeofstudy.php\#History.

45. Brim OG, Baltes PB, Bumpass LL, et al. Midlife in the United States (MIDUS 1), 1995-1996: Description of MIDUS Samples (ICPSR 2760). Ann Arbor, MI: InterUniversity Consortium for Political and Social Research [distributor]; 2019. https://doi.org/10.3886/ICPSR02760.v18.

46. Brim OG, Baltes PB, Bumpass LL, et al. Midlife in the United States (MIDUS 1), 1995-1996: Documentation of Age in MIDUS 1 and 2 (ICPSR 2760). Ann Arbor, MI: Inter-University Consortium for Political and Social Research [distributor]; n.d. https://doi.org/10.3886/ICPSR02760.v18

47. Ryff C, Almeida D, Ayanian J, et al. Midlife in the United States (MIDUS Refresher), 2011-2014: MIDUS Refresher Project 1 Field Report (ICPSR 36532). Ann Arbor, MI: Inter-University Consortium for Political and Social Research [distributor]; 2015. https://doi.org/10.3886/ICPSR36532.v3

48. Ryff C, Almeida D, Ayanian J, et al. Midlife in the United States (MIDUS Refresher), 2011-2014: MIDUS Refresher Documentation of Age (ICPSR 36532). Ann Arbor, MI: Inter-University Consortium for Political and Social Research [distributor]; 2015. https://doi.org/10.3886/ICPSR36532.v3

49. Inter-university Consortium for Political and Social Research, University of Michigan. Midlife in the United States (MIDUS) series. Ann Arbor, MI: The Regents of the University of Michigan, 2020. https://www.icpsr.umich.edu/ web/ICPSR/series/203. Accessed September 29, 2021.

50. Ryff C, Almeida DM, Ayanian JS, et al. Midlife in the United States (MIDUS 2), 2004-2006: Documentation of Psychosocial Constructs and Composite Variables in MIDUS II Project 1 (ICPSR 4652). Ann Arbor, MI: Inter-University Consortium for Political and Social Research [distributor]; 2010. https://doi. org/10.3886/ICPSR04652.v7

51. Ryff C, Almeida D, Ayanian J, et al. Midlife in the United States (MIDUS Refresher), 2011-2014: MIDUS Refresher Psychosocial Constructs and Composite Variables (ICPSR 36532). Ann Arbor, MI: Inter-University Consortium for Political and Social Research [distributor]; 2015. https://doi.org/10.3886/ ICPSR36532.v3

52. Kessler RC, Andrews G, Mroczek D, Ustun B, Wittchen HU. The World Health Organization composite international diagnostic interview short-form (CIDISF). Int J Methods Psychiatr Res. 1998;7(4):171-85. https://doi.org/10.1002/ mpr.47.

53. Walters E, Kessler R, Neslon C, Mroczek D. Scoring the World Health Organization's composite international diagnostic interview short form (CIDI-SF). Geneva, Switzerland: World Health Organization; 2002. https:// www.hcp.med.harvard.edu/ncs/ftpdir/cidisf_readme.pdf.

54. Centers for Disease Control and Prevention. Violence prevention: Behavioral Risk Factor Surveillance System ACE data. US Department of Health and 
Human Services, 2020. https://www.cdc.gov/violenceprevention/acestudy/a ce brfss.html. Accessed September 29, 2021.

55. Gender Identity in US Surveillance (GenIUSS) Group. Best Practices for Asking Questions to Identify Transgender and Other Gender Minority Respondents on Population-Based Surveys. Los Angeles, CA: The Williams Institute;2014. https://williamsinstitute.law.ucla.edu/wp-content/uploads/Survey-MeasuresTrans-GenIUSS-Sep-2014.pdf

56. Clayton JA, Tannenbaum C. Reporting sex, gender, or both in clinical research? JAMA. 2016;316(18):1863-4. https://doi.org/10.1001/jama.2016.16405.

57. Lee C, Tsenkova VK, Boylan JM, Ryff CD. Gender differences in the pathways from childhood disadvantage to metabolic syndrome in adulthood: an examination of health lifestyles. SSM Popul Health. 2018;4:216-24. https:// doi.org/10.1016/j.ssmph.2018.01.003.

58. Tsenkova VK, Lee C, Boylan JM. Childhood socioeconomic disadvantage, occupational, leisure-time, and household physical activity, and diabetes in adulthood. J Phys Act Health. 2017;14(10):766-72. https://doi.org/10.1123/ jpah.2016-0438.

59. Boylan JM, Cundiff JM, Fuller-Rowell TE, Ryff CD. Childhood socioeconomic status and inflammation: psychological moderators among black and white Americans. Health Psychol. 2020;39(6):497-508. https://doi.org/10.1037/hea 0000866.

60. Gruenewald TL, Karlamangla AS, Hu P, Stein-Merkin S, Crandall C, Koretz B, et al. History of socioeconomic disadvantage and allostatic load in later life. Soc Sci Med. 2012;74(1):75-83. https://doi.org/10.1016/j.socscimed.2011.09.037.

61. Cummings P. Estimating adjusted risk ratios for matched and unmatched data: an update. Stata J. 2011;11(2):290-8. https://doi.org/10.1177/153 6867X1101100208.

62. Baldwin JR, Reuben A, Newbury JB, Danese A. Agreement between prospective and retrospective measures of childhood maltreatment: a systematic review and meta-analysis. JAMA Psychiatry. 2019;76(6):584-93. https://doi.org/10.1001/jamapsychiatry.2019.0097.

63. Hardt J, Rutter M. Validity of adult retrospective reports of adverse childhood experiences: review of the evidence. J Child Psychol Psychiatry. 2004;45(2):260-73. https://doi.org/10.1111/j.1469-7610.2004. 00218.x.

64. Danese A, Widom CS. Objective and subjective experiences of child maltreatment and their relationships with psychopathology. Nat Hum Behav. 2020:4(8):811-8. https://doi.org/10.1038/s41562-020-0880-3.

65. McLennan JD, MacMillan HL, Afifi TO. Questioning the use of adverse childhood experiences (ACEs) questionnaires. Child Abuse Negl. 2020;101: 104331. https://doi.org/10.1016/j.chiabu.2019.104331.

66. Dong M, Anda RF, Felitti VJ, Dube SR, Williamson DF, Thompson TJ, et al. The interrelatedness of multiple forms of childhood abuse, neglect, and household dysfunction. Child Abuse Negl. 2004;28(7):771-84. https://doi. org/10.1016/j.chiabu.2004.01.008.

67. McEwen CA, Gregerson SF. A critical assessment of the adverse childhood experiences study at 20 years. Am J Prev Med. 2019;56(6):790-4. https://doi. org/10.1016/j.amepre.2018.10.016

68. American Psychological Association. Diagnostic and statistical manual of mental disorders. 4th ed. Washington, DC: American Psychiatric Association; 1994.

69. Turner HA, Finkelhor D, Mitchell K, Jones LM, Henly M. Strengthening the predictive power of screening for adverse childhood experiences (ACEs) in younger and older children. Child Abuse Negl. 2020;107:104522. https://doi. org/10.1016/j.chiabu.2020.104522.

70. Krieger $\mathrm{N}$. Measures of racism, sexism, heterosexism, and gender binarism for health equity research: from structural injustice to embodied harm —an ecosocial analysis. Annu Rev Public Health. 2020;41 (1):37-62. https://doi. org/10.1146/annurev-publhealth-040119-094017.

71. Insel T, Cuthbert B, Garvey M, Heinssen R, Pine DS, Quinn K, et al. Research domain criteria (RDoC): toward a new classification framework for research on mental disorders. Am J Psychiatry. 2010;167(7):748-51. https://doi.org/1 0.1176/appi.ajp.2010.09091379.

72. Maletic $\mathrm{V}$, Raison $\mathrm{C}$. The new mind-body science of depression. WW Norton \& Company: New York, NY; 2017

73. Helms JE, Nicolas G, Green CE. Racism and ethnoviolence as trauma: enhancing professional training. Traumatolog (Tallahass Fla). 2010;16(4):5362. https://doi.org/10.1177/1534765610389595

74. Henning JA, Brand B, Courtois CA. Graduate training and certification in trauma treatment for clinical practitioners. Train Educ Prof Psychol. [online first 4 Feb 2021$]$ 2021. https://doi.org/10.1037/tep0000326
75. Howell EF. "Good girls," sexy "bad girls," and warriors: the role of trauma and dissociation in the creation and reproduction of gender. J Trauma Dissociation. 2002;3(4):5-32. https://doi.org/10.1300/J229v03n04_02.

76. Crenshaw K. Demarginalizing the intersection of race and sex: a black feminist critique of antidiscrimination doctrine, feminist theory and antiracist politics. Univ Chic Leg Forum. 1989;1989(1):139-67.

77. Greene CA, Haisley L, Wallace C, Ford JD. Intergenerational effects of childhood maltreatment: a systematic review of the parenting practices of adult survivors of childhood abuse, neglect, and violence. Clin Psychol Rev. 2020;101891:101891. https://doi.org/10.1016/j.cpr.2020.101891.

\section{Publisher's Note}

Springer Nature remains neutral with regard to jurisdictional claims in published maps and institutional affiliations.
Ready to submit your research? Choose BMC and benefit from:

- fast, convenient online submission

- thorough peer review by experienced researchers in your field

- rapid publication on acceptance

- support for research data, including large and complex data types

- gold Open Access which fosters wider collaboration and increased citations

- maximum visibility for your research: over $100 \mathrm{M}$ website views per year

At BMC, research is always in progress.

Learn more biomedcentral.com/submissions 